\title{
Are all Granulomatous Mastitis Cases Tuberculous?: A Study on the Role of Cytology in Evaluation of Granulomatous Mastitis
}

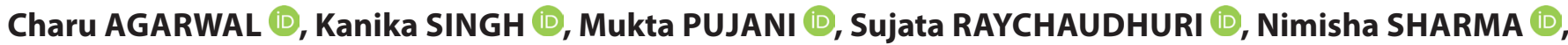 \\ Varsha CHAUHAN (D)
}

Department of Pathology, ESIC Medical College and Hospital, NIT 3, FARIDABAD, INDIA

\section{ABSTRACT}

Objective: Granulomatous mastitis is a rare inflammatory condition of the breast clinically mimicking breast carcinoma and pyogenic abscess, thereby creating a diagnostic dilemma. Tuberculous mastitis is a rare clinical entity accounting for approximately $3 \%$ of all mammary lesions. All cases of granulomatous mastitis diagnosed cytologically over a period of 3 years were evaluated to ascertain the cases with tuberculous etiology.

Material and Method: Fine needle aspiration cytology of the breast lump was performed and all the cytological parameters were evaluated. Wherever histopathology was available, the diagnosis was confirmed on Hematoxylin \& Eosin stained sections and the Ziehl Neelsen (ZN) stain was applied.

Results: A total of 10 cases of granulomatous mastitis were diagnosed on cytology during the 3-year period. On cytological smears, four cases showed presence of ill-formed granulomas and one case had scattered epithelioid histiocytes; however, the rest of the cases had well-formed granulomas. Finally, four out of ten cases were labeled as tuberculous mastitis based on the ZN stain/Tuberculosis-Polymerase chain reaction (TB-PCR) and the other six cases were granulomatous mastitis.

Conclusion: Cytology plays a significant role in the diagnosis of granulomatous mastitis. This study re-emphasizes the role of the cytopathologist in the accurate and early diagnosis of these lesions so that unnecessary surgery can be avoided, and also highlights the fact that all granulomatous mastitis cases are not tuberculous.

Key Words: Granulomatous mastitis, Tuberculous, Cytology, ZN stain, PCR, Breast

\section{INTRODUCTION}

Granulomatous mastitis (GM) is a rare inflammatory condition of the breast which can clinically mimic breast carcinoma and pyogenic abscess, thereby creating a diagnostic dilemma (1). It was first described by Kessler and Woolloch in 1972 (2). GM has an unclear etiology and variable treatment options and has a tendency to persist or recur $(3,4)$. In Asian countries, the etiology of most cases is tuberculosis but other rare causes of granulomatous conditions include fungal diseases, sarcoidosis and Wegener's granulomatosis. Idiopathic Granulomatous Mastitis (IGM) is therefore a diagnosis of exclusion.

GM is a benign condition but it is crucial to arrive at a correct diagnosis at an early stage so that an unnecessary surgery can be avoided due to its resemblance to carcinoma both clinically and radiologically.

Tuberculous mastitis is a rare clinical entity accounting for approximately $3 \%$ of all mammary lesions mainly

(Turk Patoloji Derg 2019, 35:128-133)

Received : 24.07.2018 Accepted : 18.09.2018 affecting Indian and African females and is often clinically misdiagnosed as other benign or malignant lesions of the breast (5). It may occur as a part of systemic tuberculosis or as an isolated lesion.

Although histopathology remains the gold standard for establishing the correct diagnosis, FNAC plays a pivotal role in the early diagnosis of GM as a minimally invasive, simple and cost effective outpatient technique. Thereby, a correct etiological diagnosis of granulomatous lesions is mandatory so as to administer appropriate therapy.

Here we are presenting a series of 10 cases of granulomatous mastitis diagnosed cytologically over a period of 3 years. Through this study, we wish to re-emphasize that all granulomatous mastitis cases are not tuberculous, even in the endemic countries like India as documented by several other authors $(6,7)$. Moreover, it highlights the role of cytopathologist in the accurate and early diagnosis of these lesions so that unnecessary surgery can be avoided.

Correspondence: Mukta PUJANI

Department of Pathology, ESIC Medical College and Hospital,

FARIDABAD, HARYANA, 121001, INDIA

E-mail: drmuktapujani@gmail.com Phone: +93 13850205 


\section{MATERIAL and METHODS}

The current study was performed at the Department of Pathology, ESIC Medical College and Hospital, Faridabad over a period of 3 years (April 2015 to April 2018). The cases were retrieved from the archives of the cytopathology and histopathology laboratories. All cases reported as granulomatous mastitis on cytology were included in the study.

The patients presented to surgical outpatient department with a breast lump and were referred to the cytopathology laboratory. Fine needle aspiration cytology (FNAC) of the lump was performed and smears were evaluated. In all the cases, cytological parameters were evaluated including the presence of epithelioid cell granulomas, histiocytes, multinucleated giant cells, necrosis and neutrophils. The Ziehl Neelsen (ZN) stain for acid fast bacilli (AFB) and Periodic acid Schiff (PAS) stain for fungi were performed on all cytological cases. The clinical details including gender, age, history of trauma, family history of TB along with radiological findings (if available) of all the patients were recorded. Routine hematological findings with the Erythrocyte sedimentation rate (ESR) and Mantoux test along with the Tuberculosis-Polymerase chain reaction (TB-PCR) were correlated. Wherever histopathology was available, the diagnosis was confirmed on Hematoxylin and eosin stained sections and the ZN stain was applied.

\section{RESULTS}

A total of 10 cases of granulomatous mastitis were diagnosed on cytology during the 3-year period. All the patients were female with a mean age of 36 years (range,
29-51). In six out of ten cases, the lesion was in the right breast and four were on the left side, while the size of the lump varied from 1 to $5 \mathrm{~cm}$ in diameter. The duration of the lump ranged from 1 month to two years. All the cases had varied clinical presentations with few showing an irregular hard lump and were given provisional clinical diagnosis of abscess, fibroadenoma and malignancy. One case had a past history of being operated for abscess but few months later she again developed a lump that turned out to be granulomatous mastitis.

Ultrasonography was done in 7 cases and was reported variably as abscess, irregular hypoechoic mass, increased vascularity and lobulated mass, thereby creating a dilemma.

The clinico-pathological details of all the cases are shown in Table I.

On fine needle aspiration, blood mixed aspirate was obtained in all cases barring two where pus was aspirated. On cytological smears (Figure 1,2), four cases showed the presence of ill-formed granulomas, one case had scattered epithelioid histiocytes and the rest of the cases had wellformed granulomas. Four cases showed absence of necrosis with one case showing patchy necrosis and the other five cases showing abundant caseous necrosis. Multinucleated giant cells, containing nuclei ranging from 5 to 18 , were present in six cases. These six cases also had predominance of neutrophils among other inflammatory cells forming micro abscesses. Three cases showed the presence of benign ductal cells of the breast (Figure 1). The cytological features of all the cases are depicted in Table II. On application of $\mathrm{ZN}$ stain, three cases showed presence of AFB (Figure 2A,B) thereby confirming the diagnosis of TB mastitis, which was

Table I: Clinicopathological details of all cases.

\begin{tabular}{cccccccccc}
\hline Cases & $\begin{array}{c}\text { Age } \\
(\mathbf{y r s})\end{array}$ & Site & Mantoux & ESR & USG & Clinical & CYTO & TB-PCR & Histo \\
\hline Case 1 & 29 & Right & Negative & 24 & Abscess & Fibroadenoma & GM & Negative & GM \\
\hline Case 2 & 32 & Right & Positive & 27 & Irregular mass & Malignancy & GM & Negative & GM \\
\hline Case 3 & 51 & Left & Negative & 22 & - & Fibroadenoma & GM & Negative & - \\
\hline Case 4 & 31 & Right & Positive & 38 & Hypoechoic mass & TB & TBM & Positive & TBM \\
\hline Case 5 & 34 & Right & Positive & 23 & Abscess & Abscess & GM & Negative & - \\
\hline Case 6 & 41 & Left & Negative & 31 & - & Abscess & GM & Positive & - \\
\hline Case 7 & 24 & Left & Negative & 25 & Increased vascularity & Malignancy & GM & Negative & GM \\
\hline Case 8 & 35 & Right & Positive & 23 & - & Fibroadenoma & GM & Negative & - \\
\hline Case 9 & 36 & Left & Positive & 34 & Mass with lobulated margins & Fibroadenoma & TBM & Positive & TBM \\
\hline Case 10 & 45 & Right & Positive & 42 & Irregular & Malignancy & TBM & Positive & TBM \\
\hline
\end{tabular}

ESR: Erythrocyte sedimentation rate, USG: Ultrasonography, CYTO: Cytology, TB-PCR: Tuberculosis- Polymerase Chain Reaction, Histo: Histopathology, GM: Granulomatous mastitis, TBM: Tuberculous mastitis 


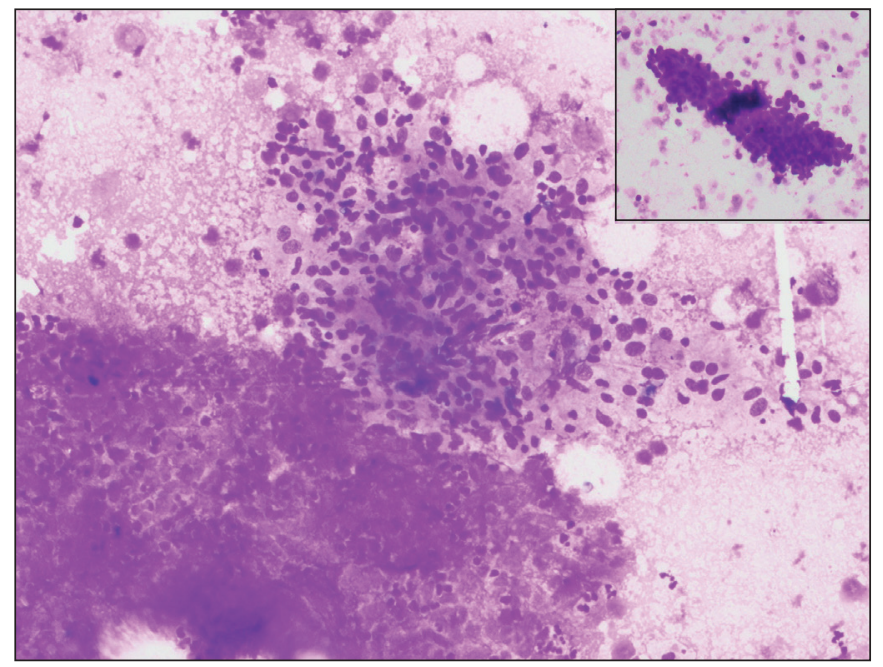

Figure 1: Giemsa stained smears showing well-formed granuloma with patchy necrosis (Giemsa; x400) (Inset - showing benign ductal cells cluster) (Case 5).

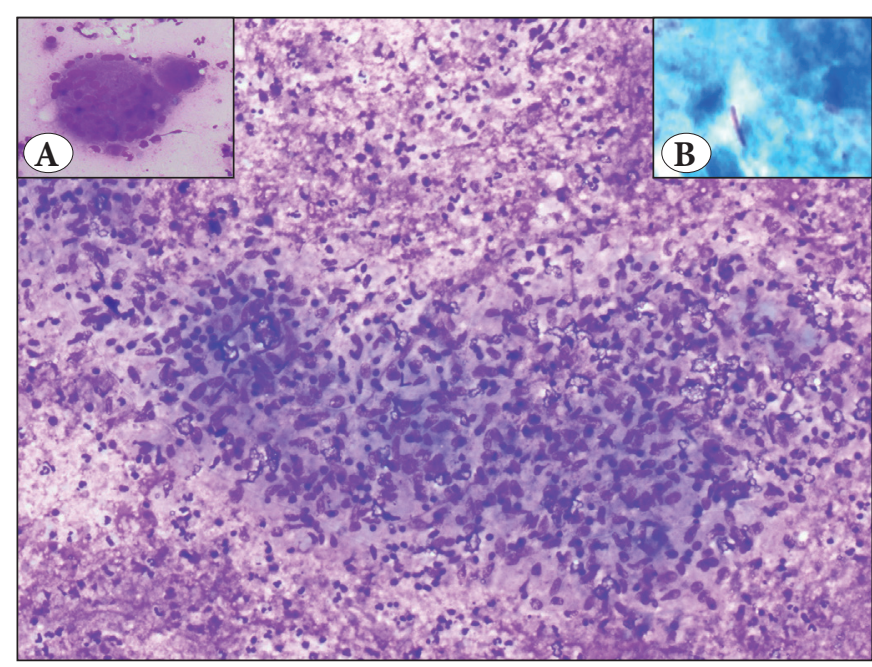

Figure 2: Giemsa stained smears showing well-formed granuloma in a background of degenerated inflammatory cells (Giemsa; x400). Inset: A) Giant cell (Giemsa;x200). B) AFB bacilli (ZN stain; x1000) (Case 9).

Table II: Spectrum of cytological features of all the cases of GM.

\begin{tabular}{|c|c|c|c|c|c|c|c|c|}
\hline Cases & Granuloma & Necrosis & $\begin{array}{c}\text { Acute } \\
\text { inflammation }\end{array}$ & $\begin{array}{l}\text { Giant } \\
\text { cells }\end{array}$ & $\begin{array}{c}\text { Ductal } \\
\text { cells }\end{array}$ & AFB & TB-PCR & Cytology \\
\hline Case 1 & present & present & absent & occasional & occasional & negative & Negative & GM \\
\hline Case 2 & present & absent & present & present & absent & negative & Negative & GM \\
\hline Case 3 & ill formed & absent & absent & absent & occasional & negative & Negative & GM \\
\hline Case 4 & present & present & absent & absent & absent & present & Positive & TBM \\
\hline Case 5 & present & patchy & present & present & absent & negative & Negative & GM \\
\hline Case 6 & ill formed & absent & present & present & absent & negative & Positive & $\mathrm{GM}^{*}$ \\
\hline Case 7 & ill formed & absent & absent & absent & absent & negative & Negative & GM \\
\hline Case 8 & Epithelioid histiocytes & present & present & present & occasional & negative & Negative & GM \\
\hline Case 9 & present & present & present & present & absent & present & Positive & TBM \\
\hline Case 10 & ill formed & present & present & present & absent & present & Positive & TBM \\
\hline
\end{tabular}

${ }^{\star}$ Case 6 was TB-PCR positive, so was finally labelled as TBM.

AFB: Acid fast bacilli, GM: Granulomatous mastitis, TBM: Tuberculous mastitis, TB-PCR: Tuberculosis-Polymerase chain reaction.

further reaffirmed on histopathology. The PAS stain for fungus was negative in all the cases. TB-PCR was sent for all cases that turned out to be granulomatous mastitis on cytology (as depicted in Table II) and four were positive. Three out of these four cases (TB-PCR positive) underwent surgical excision. So finally four out of ten cases were labeled as tuberculous mastitis. On reviewing the histories of patients with GM, none of the patients had any evidence of Crohn's, sarcoidosis, etc.

Six cases underwent surgery and tissue was sent for histopathological examination. On histopathology (Figure $3 \mathrm{~A}, \mathrm{~B})$, four cases showed the presence of well-formed epithelioid cell granulomas but the remaining two cases had an ill-formed granulomas. There were multinucleated giant cells and necrosis in four cases. The surrounding breast showed features of adenosis. Three cases were diagnosed histologically as TB mastitis and the other three cases showed features suggestive of granulomatous mastitis since they were negative on $\mathrm{ZN}$ staining (Table I).

\section{DISCUSSION}

Granulomatous mastitis (GM) is an uncommon breast lesion that was first described in 1972 and representing approximately $0.025-3 \%$ of all surgically treated breast diseases $(2,8)$. 
The etiology of GM is diverse, ranging from infectious causes including bacterial (TB, Leprosy, Cat-scratch disease), fungal (histoplasmosis, cryptococcosis), protozoal (schistosomiasis) to autoimmune causes including Crohn's, sarcoidosis, vasculitis as well as a reaction to foreign bodies/ implants (silicon, beryllium) $(9,10)$. Therefore, idiopathic GM is a diagnosis of exclusion.

The disease usually occurs in women of reproductive age, and may be associated with lactation or the postpartum period. Affected women are nearly always parous and usually present in their early thirties with the progressive onset of a breast lump (11). All patients in the present study were in the reproductive age group, not associated with lactation or lymph node involvement.

The most common clinical presentation is a firm, unilateral, discrete breast mass, often associated with inflammation of the overlying skin. The disease course is characterized by slow resolution, occasionally with intermittent episodes of abscess or discharging sinus formation, particularly after large core needle biopsies ${ }^{3,12}$ as in one of the cases in the present study. It is well known for its worrisome clinical presentation as a hard breast lump with or without nipple retraction particularly in young women, thereby acting as a mimic of carcinoma clinically as documented by several authors $(2,7,10,12,13)$. Regional lymphadenopathy may be present in up to $15 \%$ of cases (14). It often masquerades as other common conditions such as breast abscess, fibroadenoma, etc. Similarly, our three cases were misdiagnosed clinically as carcinoma.

The breast and skin are considered to be the rarest sites of extrapulmonary tuberculosis constituting only approx. 0.1$0.5 \%$ of all TB cases (8). Tuberculosis (TB) of the breast is an uncommon disease that is often difficult to differentiate from cancer of the breast when it presents as a lump, as mistakenly done in one of our cases.

FNAC is the primary investigation for breast lesions so awareness about GM is a must among cytopathologists. The common cytological features that have been evaluated include necrosis, giant cells, epithelioid histiocytes, granulomas, and neutrophils present in the background. FNAC may not always differentiate between IGM and other granulomatous diseases of the breast, and a confident diagnosis may require histological samples, negative microbiological investigations and clinical correlation. Its histopathological features are characterized by chronic, necrotizing granulomatous lobulitis. As IGM is essentially a diagnosis of exclusion, and all causes of granulomatous inflammation must be actively excluded by applying special tests like AFB (TB bacilli), PAS (fungus), Gram stain (bacterial), PCR (TB or atypical mycobacterium), etc. The cases in the present study were all properly worked up clinically and cytologically with histopathological work up in six out of ten cases.
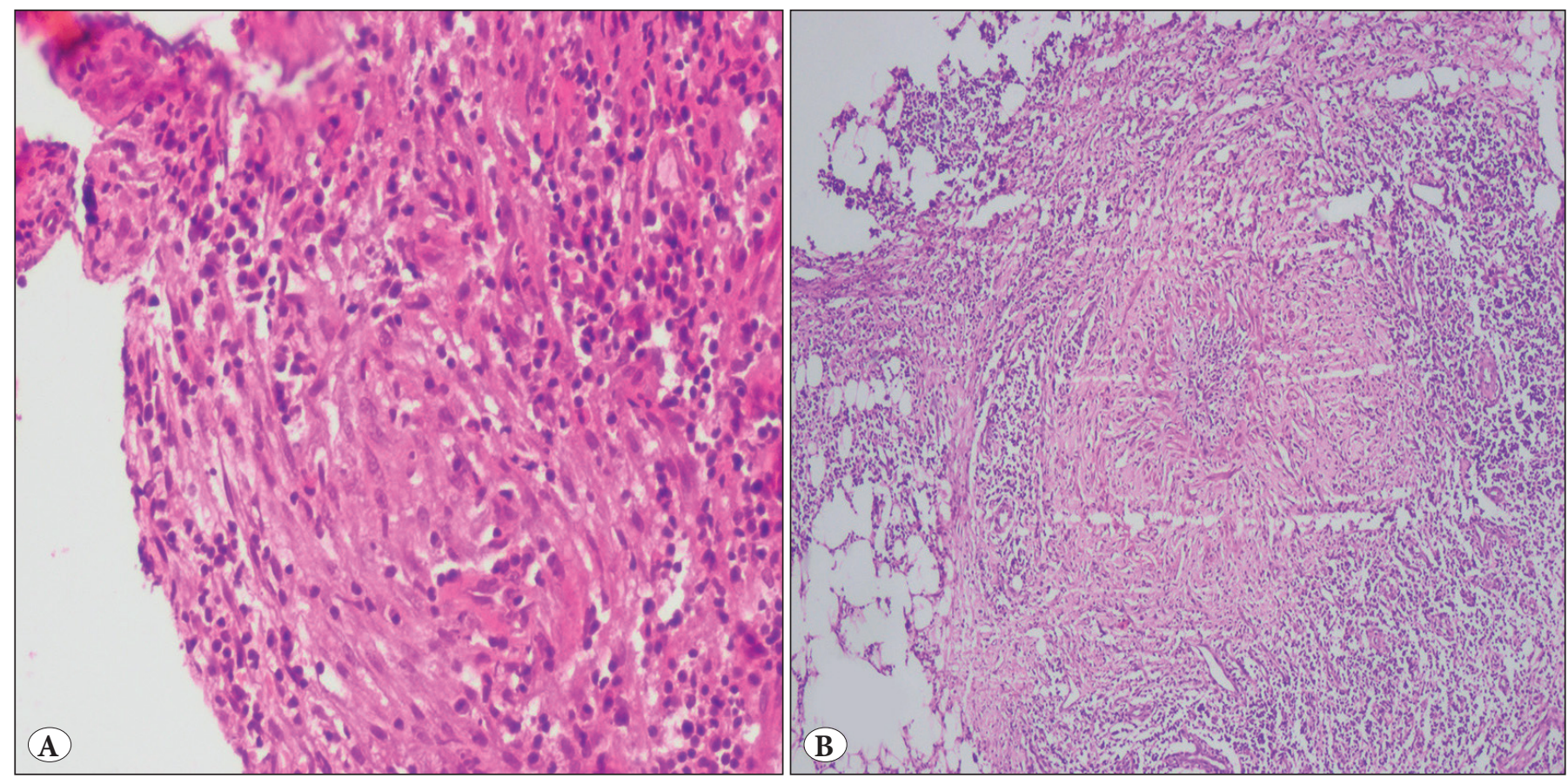

Figure 3: A) Photomicrograph showing an ill-formed granuloma (H\&E; x400) (Case 10). B) Photomicrograph showing an well-formed granuloma (H\&E; x100) (Case 1). 
During our extensive search of the literature on GM, we came across several studies across the globe. Seo et al. in 2012 retrospectively reviewed the records of 68 patients with GM. FNAC was performed in 30 cases with histopathology in all 68 patients, out of which 10 cases were TBM (tuberculous mastitis) while IGM was the final diagnosis in the rest of them (15). Helal et al. studied 65 cases of IGM over a period of 6 years. They have explained cytomorphological and histomorphological features of IGM (16). They emphasized the efficacy of cytology in the diagnosis of such lesions. Ail et al. obtained 21 cases of granulomatous mastitis diagnosed on cytology over eight years, out of which 16 cases were of non specific GM and five were TBM (6). They found that $25 \%$ of non specific GM and $60 \%$ of TBM cases had a clinical suspicion of malignancy and about $30 \%$ had a radiological suspicion of malignancy. In the present study, we evaluated 10 cases of GM over a period of 3 years. Cytological parameters were evaluated in all the cases with applications of special tests like the ZN and PAS stain. Histopathological correlation was done wherever possible. Four out of ten cases were labelled as tuberculous mastitis based on the ZN stain/ Tuberculosis-Polymerase chain reaction (TB-PCR) and the remaining six cases were IGM. The comparative analysis of various studies (pubmed literature search) based on cytopathological evaluation of GM is depicted in Table III.

In a review by Benson and Dumitru (9), they favoured a multidisciplinary approach for the treatment of IGM as there is no consensus on the optimal treatment strategy. Before adopting a surgical approach, the pros and cons should be carefully weighed for individual cases so as to avoid the worrisome complications arising out of surgery (9). Treating tuberculosis with steroids would aggravate the infection, whereas giving unnecessary anti-tuberculosis drugs in cases of idiopathic granulomatous mastitis may cause numerous side effects. Therefore it is mandatory to differentiate these two lesions before commencement of therapy.

In conclusion, cytology plays a significant role in the diagnosis of GM. All granulomatous mastitis cases are not tuberculous and the etiological diagnosis of GM must be based on a multidisciplinary approach. The definitive diagnosis of GM relies on correlation with histopathological and microbiological investigations. This study re-emphasizes the role of the cytopathologist in the accurate and early diagnosis of these lesions so that unnecessary surgery can be avoided.

Table III: Comparative analysis of various studies (pubmed literature search) based on cytopathological evaluation.

\begin{tabular}{|c|c|c|c|c|c|c|c|c|}
\hline $\begin{array}{l}\text { S. } \\
\text { No }\end{array}$ & Year & Authors & $\begin{array}{c}\text { Location of } \\
\text { study }\end{array}$ & $\begin{array}{l}\text { Duration } \\
\text { (years) }\end{array}$ & $\begin{array}{c}\text { No. } \\
\text { of } \\
\text { cases }\end{array}$ & $\begin{array}{c}\text { No. of TB mastitis } \\
\text { (AFB/TB-PCR } \\
\text { positive) }\end{array}$ & $\begin{array}{c}\text { Histological } \\
\text { correlation }\end{array}$ & Comments \\
\hline 1. & 1999 & Yip et al. ${ }^{17}$ & Malaysia & 3 & 16 & - & 10 & All cases of IGM \\
\hline 2. & 2003 & Elsiddig et al. ${ }^{18}$ & Sudan & 10 & 11 & 9 & 1 & - \\
\hline 3. & 2003 & Tse et $\mathrm{al}^{19}$ & Hong Kong & 12 & 8 & - & 8 & All cases of IGM \\
\hline 4. & 2009 & $\begin{array}{c}\text { Nemenqani et } \\
\text { al. }^{8}\end{array}$ & $\begin{array}{l}\text { Saudi } \\
\text { Arabia }\end{array}$ & 8 & 15 & 2 & - & $\begin{array}{c}\text { Total } 49 \text { cases of } \\
\text { inflammatory breast } \\
\text { lesions studied }\end{array}$ \\
\hline 5. & 2010 & $\begin{array}{l}\text { Gangopadhyay } \\
\text { et al. }{ }^{20}\end{array}$ & India & 5 & 8 & - & 8 & All cases of IGM \\
\hline 6. & 2010 & Gupta et al. ${ }^{4}$ & $\begin{array}{c}\text { New } \\
\text { Zealand }\end{array}$ & 27 & 18 & - & 12 & TB mastitis excluded \\
\hline 7. & 2011 & Atalay et al. ${ }^{21}$ & Turkey & 5 & 51 & - & 51 & All cases of IGM \\
\hline 8. & 2012 & Seo et al. ${ }^{15}$ & Korea & 10 & 68 & 10 & 68 & $\begin{array}{c}\text { FNAC was performed in } \\
30 \text { cases }\end{array}$ \\
\hline 9. & 2016 & Helal et al. ${ }^{16}$ & Egypt & 6 & 65 & - & 65 & All cases of IGM \\
\hline 10. & 2017 & Ail et al. ${ }^{6}$ & India & 8 & 21 & 5 & 4 & - \\
\hline 11. & 2018 & Present study & India & 3 & 10 & 4 & 6 & - \\
\hline
\end{tabular}

AFB/TB-PCR: Acid fast bacilli/Tuberculosis-Polymerase chain reaction, IGM: Idiopathic granulomatous mastitis, FNAC: Fine needle aspiration cytology. 


\section{CONFLICT of INTEREST}

The authors declare no conflict of interest.

\section{REFERENCES}

1. Bakaris S, Yuksel M, Ciragil P, Guven MA, Ezberci F, Bulbuloglu E. Granulomatous mastitis including breast tuberculosis and idiopathic lobular granulomatous mastitis. Can J Surg. 2006;49:427-30.

2. Kessler E, Woolloch Y. Granulomatous mastitis: A lesion clinically simulating carcinoma. Am J Clin Pathol. 1972;58:6426.

3. Stary CM, Lee YS, Balfour J. Idiopathic granulomatous mastitis associated with Corynebacterium species. Hawaii Med J. 2011;70:99-101.

4. Gupta RK. Fine needle aspiration cytology of granulomatous mastitis: A study of 18 cases. Acta Cytol. 2010;54:138-41.

5. Tauro LF, Martis JS, George C, Kamath A, Lobo G, Hegde BR. Tuberculous mastitis presenting as breast abscess. Oman Med J. 2011;26:53-5.

6. Ail DA, Bhayekar P, Joshi A, Pandya N, Nasare A, Lengare P, Narkhede KA. An eight year study of granulomatous mastitis and utility of FNAC in picking up tubercular mastitis. J Clin Diagn Res. 2017;11:EC45-EC49.

7. Kamra HT, Munde SL, Rana P, Kaur S, Singh K, Duhan A. Cytological features of granulomatous mastitis- A study of ten cases. IJPO. 2016;3:129-32.

8. Nemenqani D, Yaqoob N, Hafiz M. Fine needle aspiration cytology of granulomatous mastitis with special emphasis on microbiologic correlation. Acta Cytol. 2009;53:667-71.

9. Benson JR, Dumitru D. Idiopathic granulomatous mastitis: Presentation, investigation and management. Future Oncol. 2016;12:1381-94.

10. Hoda SA. Inflammatory and reactive tumors. In Hoda SA, Brogi E, Koerner FC, Rosen PP, editors. Rosen's breast pathology. $4^{\text {th }}$ ed. Philadelphia:Wolters Kluwer Health; 2014. 37-78.
11. Jorgensen MB, Nielsen DM. Diagnosis and treatment of granulomatous mastitis. Am J Med. 1992;93:97-101.

12. Tse GM, Poon CS, Law BK, Pang LM, Chu WC, Ma TK. Fine needle aspiration cytology of granulomatous mastitis. J Clin Pathol. 2003;56:519-21.

13. Gurleyik G, Aktekin A, Aker F, Karagulle H, Saglam A: Medical and surgical treatment of idiopathic granulomatous lobular mastitis: A benign inflammatory disease mimicking invasive carcinoma. J Breast Cancer. 2012;15:119-23.

14. Donn W, Rebbeck P, Wilson C, Gilks CB. Idiopathic granulomatous mastitis: A report of three cases and review of the literature. Arch Pathol Lab Med. 1994;118:822-5.

15. Seo HRN, Na KY, Yim HE, Kim TH, Kang DK, Oh KK, Oh KK, Kang SY, An YS, Chun M, Kim W, Park RW, Jung YS, Kim KS. Differential diagnosis in idiopathic granulomatous mastitis and tuberculous mastitis. J Breast Cancer. 2012;15:111-8.

16. Helal TEA, Shash LS, Saad El-Din SA, Saber SM. Idiopathic granulomatous mastitis: Cytologic and histologic study of 65 Egyptian patients. Acta Cytol. 2016;60:438-44.

17. Yip CH, Jayaram G, Swain M. The value of cytology in granulomatous mastitis: A report of 16 cases from Malaysia. Aust. N.Z. J. Surg. 2000;70,103-5.

18. Elsiddig KE, Khalil EAG, Elhag IA, Elsafi MEMO, Suleiman GM, Elkhidir IM, Hussein AM, El-Hassan AM: Granulomatous mammary disease: Ten years' experience with fine needle aspiration cytology. Int J Tuberc Lung Dis. 2003;7:365-9.

19. Tse GM, Poon CS, Ramachandram K, Ma TK, Pang LM, Law BK, Chu WC, Tang AP, Cheung HS: Granulomatous mastitis: A clinicopathological review of 26 cases. Pathology. 2004, 36: 2547 .

20. Gangopadhyay M, De A, Chakrabarti I, Ray S, Giri A, Das R. Idiopathic granulomatous mastitis-utility of fine needle aspiration cytology (FNAC) in preventing unnecessary surgery. J Turkish-German Gynecol Assoc. 2010; 11: 127-30.

21. Atalay C, Kizıltan G, Ozaslan C, Pak I. Idiopathic granulomatous mastitis. Journal of Breast Health 2011;7:203-6. 